RESEARCH

Journal of Critical Dietetics

ISSN 1923-1237

Vol 6, Issue 2

Copyright 2022

Toronto, ON

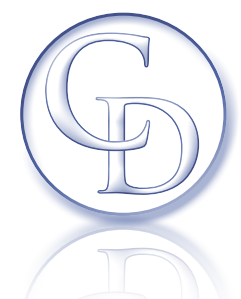

\title{
A survey of Registered Dietitian Nutritionists who provide care to clients with eating disorders: Implications for education, training and clinical practice.
}

Jessica Setnick, MS, RDN, LD, CEDRD-S; Kerrin Meseck, MS, RDN; Jordan Tackett, MS, RDN, LDN, CNSC; and Paula A. Quatromoni, DSc, MS, RDN, LDN

\begin{abstract}
Successful management of eating disorder (ED) symptoms includes Registered Dietitian Nutritionists (RDNs) with specialized expertise, nutrition counseling skills, and advanced training. We conducted an anonymous on-line survey of self-identified ED-specialized RDNs about their previous education and training, workload, job duties, and job satisfaction. Respondents were 182 RDNs who were U.S. members of the International Federation of Eating Disorder Dietitians. Qualitative methods identified salient themes from narrative responses to augment survey data. Most respondents expressed confidence in their ED-related competence, however these skills were gained from post-professional, self-funded activities, not from ED-specific education or training in either school or work settings. While two-thirds of RDNs surveyed held an advanced degree and more than half held specialty certification, an inverse relationship between provider expertise and patient acuity was observed. RDNs working at the highest levels of ED care with the most medically complex patients were less likely to hold graduate degrees or have prior clinical experience. Obstacles to job satisfaction included high patient caseloads, low compensation, lack of employer support, and high burnout. Facilitators of job satisfaction included professional and client communities, and the private practice setting. Considering the essential nature of nutrition rehabilitation in ED treatment and the high prevalence of dysfunctional eating behaviors in society at-large, these observations identify gaps in RDN preparedness and facility staffing practices that may affect treatment outcomes for individuals with known and undiagnosed ED's. Enhancements in dietetics education and heightened attention to supervision for entry-level clinicians in ED-specific treatment programs are prime targets for action.
\end{abstract}

Keywords: Registered Dietitian Nutritionist (RDN), eating disorders, survey research, dietetics education, job satisfaction

\section{Introduction}

Eating disorders are complex psychiatric illnesses with biological, environmental and stress-related aspects that require significant nutrition intervention. The integral role of the registered dietitian/nutritionist (RDN) in successful eating disorder treatment and the importance of nutritional counseling are well documented and include nutrition assessment, nutrition diagnosis, nutrition intervention, nutrition monitoring and evaluation, and coordination of care among others (Ozier \& Henry, 201l; Tholking et al, 201l; American Psychiatric Association, 2000; Setnick, 2012). However, specific job duties, on-the-job training, and patient caseloads vary widely across treatment settings, and no published survey of eating disorder dietitians has been done to examine any trends that may exist. 
Previous research reported that ED RDNs in North America express dissatisfaction with the amount of formal training related to ED care they received as undergraduates and dietetic interns (Ozier \& Henry, 2010; Cairns \& Milne, 2006). The Accreditation Council for Education in Nutrition and Dietetics (ACEND) determines the topics in which RDN candidates are required to demonstrate competency; nutrition care of individuals with ED diagnoses is not one of those topics. The Academy of Nutrition and Dietetics recognizes that ED care is not included in the ACEND curriculum or in most dietetics education and training programs, and through its Standards of Practice and Professional Performance (Tholking et al, 20ll) recommends specialized training, continuing professional education and mentored supervision for RDNs who wish to work in this area. It is unclear whether this additional training and education is intended to be obtained while in the workplace, at the RDN's personal expense, or otherwise. Since advanced training obtained outside of the school or work environment can be costly, limited in availability, and inaccessible, it seems likely that gaps in knowledge and skills may exist. The resulting implications on the quality of ED patient care, treatment outcomes, and patient experiences of treatment could be significant.

Separately, it is incorrect to presume that only EDspecialized RDNs are working with individuals with eating disorders. First there is the limited applicability of the "official" ED diagnoses as determined by the American Psychiatric Association (APA, 2016), the International Classification of Diseases (WHO, 1993), and the Diagnostic and Statistical Manual of Mental Disorders (APA 2013), which leave many individuals who are clearly experiencing EDs without an appropriate diagnosis. There is the ubiquity of dysfunctional eating behaviors that may not rise to the level of diagnosable EDs. And most egregiously, there are the racist, fatphobic and otherwise biased research and assessment practices that have resulted in dramatic under-diagnosing of ED's in individuals belonging to historically excluded groups (Gordon, 2006; Marques et al, 201I). Together, these factors result in only a fraction of individuals with ED's ever receiving specialized ED care. It is certain that many receive no nutrition-related care at all. But of those who do, a large proportion will receive it from non-specialized RDNs. To suggest that only those RDNs who intend to specialize in ED care will require EDrelated nutrition counseling skills is at best naïve. At worst, it willfully perpetuates ongoing systemic bias.
An example from the field of diabetes confirms the concern about unmet training needs for RDNs. A 2018 survey published by the Academy identified a prominent gap in knowledge and available resources for generalist RDNs who care for patients with diabetes compared to those with advanced training credentials in diabetes care (Bisanz et al, 20l8). The need for post-professional education and training is not unique to the practice area of diabetes care. How this unmet need relates to scope of practice and job satisfaction for the RDN working in eating disorder care has not been studied.

Our overarching research question is whether RDNs who provide care to patients with eating disorders are adequately prepared to do their jobs. The objectives of this study were to: I) identify the education, training and professional development needs of RDNs working in eating disorder treatment settings; and 2) to identify their job responsibilities and characterize job satisfaction.

\section{Methods}

This cross-sectional survey research involving RDNs who provide care to patients with eating disorder diagnoses was approved by the Institutional Review Board (IRB) at Boston University. The base population was RDN members of the International Federation of Eating Disorder Dietitians (IFEDD), a worldwide membership organization established in 2012 that is open to credentialed nutrition professionals working in this area of practice. The mission of IFEDD is to improve the quality of care of individuals with eating disorders by improving their access to appropriate treatment (IFEDD, 202I). Adults eligible for this study were English-speaking RDN members of IFEDD with a U.S. mailing address. No other exclusion criteria were applied.

Survey questions were developed to gather information on: demographics; education, training and specialty credentials; work setting and experience; roles and responsibilities as an eating disorder RDN; and job satisfaction. Response formats offered multiple choice options (including "other" or "check all that apply," when applicable) or likert rating scales. A final narrative text box allowed respondents to provide any additional comments they wanted to share. The survey was pilot tested using a convenience sample of 12 RDNs working in all levels of ED care and was revised. Time for completion was estimated at 20-30 minutes.

An invitation to participate in an anonymous, on-line survey was emailed to 649 IFEDD dietitian members 
who had a working email address on file (about $81 \%$ of U.S. members). The email included an explanation of the study and embedded survey link. The first section of the survey provided IRB-approved informed consent language and participants provided consent by commencing with the survey. Follow-up reminder emails to prompt participation, achieve a high response rate and minimize the risk of bias were sent at 2 weeks and 4 weeks. Responses were collected over a 3-month period in 2018.

Descriptive statistics were computed to generate mean $+/$ - standard deviation estimates for quantitative measures and frequencies were determined for categorical responses. All "other" narrative text responses were coded and summarized. Responses typed into the text box at the end of the survey were copied and pasted verbatim into a spreadsheet. Content analysis was applied to identify themes and classification codes were created during the analysis to organize qualitative data. Two authors reviewed the qualitative analysis, providing triangulation to increase validity and reliability of the analysis and to minimize bias (Harris et al, 2009).

\section{Results}

\section{Sample Demographics, Education and Credentials.}

We had 182 respondents to our survey yielding a $28 \%$ response rate. The sample was almost entirely female with largest representation from the northeastern U.S. (Table I). More than half were employed full time and the average length of experience in practice as an RDN was $14.8+/$ - 10.7 years (range, I to 43 years) with $11.5+/-8.6$ years, on average (range I to 38 years), working in an ED treatment setting. More than threequarters reported currently working in private practice, with about one-quarter employed by ED specialty care facilities and fewer working in other settings. The large majority of respondents worked in the outpatient level of care. One-quarter worked in intensive outpatient or partial hospitalization program with fewer working in higher levels of care (residential and inpatient). All 182 respondents provided care to adults, most treated adolescents, some treated athletes, and few treated children. Almost three-quarters reported that all or most of the clients in their practice have an ED diagnosis. The most commonly reported patient caseload was $20: 1$, with reports ranging from as low as $4: 1$ to as high as 25:1.
Of the 165 RDNs who provided information on their highest degree earned, about two-thirds $(n=I I I)$ held a master's degree. RDNs who held master's degrees were more likely to work in private practice and outpatient settings (82\%); only one-quarter of RDNs with a master's degree worked in an ED treatment facility, and $14 \%$ worked in a medical or psychiatric hospital. Almost two-thirds of respondents held a specialty credential beyond the RDN. Of that subgroup, more than half held the Certified Eating Disorder Registered Dietitian (CEDRD) credential administered by the International Association of Eating Disorder Professionals (IAEDP).

Table I. Demographic and practice characteristics of respondents to a survey of U.S. dietitians working in eating disorder treatment

\begin{tabular}{|c|c|}
\hline $\begin{array}{l}\text { Characteristic (\# of } \\
\text { respondents) }\end{array}$ & $\begin{array}{c}n(\%) \\
\text { or mean +/- SD } \\
(\min , \max )\end{array}$ \\
\hline Female (I63) & 161 (98.8\%) \\
\hline $\begin{array}{l}\text { Years in practice as an } \\
\text { RDN }^{\mathrm{a}}(166)\end{array}$ & $\begin{array}{l}14.8+/-10.7 \\
\quad(1,43)\end{array}$ \\
\hline $\begin{array}{l}\text { Years in eating disorder } \\
\text { practice }(182)\end{array}$ & $\begin{array}{l}11.5+/-8.6 \\
\quad(1,38)\end{array}$ \\
\hline Employed full-time (I78) & $104(58.4 \%)$ \\
\hline \multicolumn{2}{|l|}{ Highest degree completed (165) } \\
\hline Bachelor's & $33(20 \%)$ \\
\hline $\begin{array}{l}\text { Some graduate credits } \\
\text { (non-degree) }\end{array}$ & $10(6.1 \%)$ \\
\hline Master's & III (67.3\%) \\
\hline Doctorate & $4(2.4 \%)$ \\
\hline Other & $7(4.2 \%)$ \\
\hline \multicolumn{2}{|c|}{ Credentials beyond the RDN ${ }^{a, b}(I I 8)$} \\
\hline CEDRDc & $72(61 \%)$ \\
\hline $\mathrm{CSSD}^{\mathrm{d}}$ & $16(13.6 \%)$ \\
\hline $\begin{array}{l}\text { LICSWe or other mental health } \\
\text { certification }\end{array}$ & II (9.3\%) \\
\hline $\mathrm{CDE}^{f}$ & $10(8.5 \%)$ \\
\hline Fitness industry certification & $8(6.8 \%)$ \\
\hline CEDS: & $3(2.5 \%)$ \\
\hline Other & $16(13.6 \%)$ \\
\hline \multicolumn{2}{|l|}{ Practice setting $(182)$} \\
\hline Private Practice & $140(76.9 \%)$ \\
\hline Eating disorder treatment facility & $47(26.4 \%)$ \\
\hline Medical hospital & $15(8.2 \%)$ \\
\hline College or university & $15(8.2 \%)$ \\
\hline Psychiatric hospital & $9(4.9 \%)$ \\
\hline
\end{tabular}




\begin{tabular}{|c|c|}
\hline $\begin{array}{l}\text { Outpatient or community } \\
\text { health center }\end{array}$ & $4(2.2 \%)$ \\
\hline \multicolumn{2}{|l|}{ Level of care ${ }^{b}(182)$} \\
\hline Outpatient & $164(90.1 \%)$ \\
\hline IOP or $\mathrm{PHP}^{\mathrm{h}}$ & $47(25.8 \%)$ \\
\hline Residential program & $17(9.3 \%)$ \\
\hline Inpatient & $18(9.9 \%)$ \\
\hline \multicolumn{2}{|l|}{ Client Demographic ${ }^{\mathrm{b}}(\mathrm{I82})$} \\
\hline Adults & $182(100 \%)$ \\
\hline Adolescents & $157(86.3 \%)$ \\
\hline Athletes & $111(61 \%)$ \\
\hline Children & II (6\%) \\
\hline \multicolumn{2}{|l|}{ Patient Caseload (182) } \\
\hline $\begin{array}{l}\text { Sees } 11 \text {-20 clients per week, on } \\
\text { average }\end{array}$ & $79(43.4 \%)$ \\
\hline $\begin{array}{l}\text { All or most clients have } \\
\text { ED diagnoses }\end{array}$ & $134(74 \%)$ \\
\hline \multicolumn{2}{|l|}{ Region of the U.S. (166) } \\
\hline Northeast & $45(27.1 \%)$ \\
\hline South & $32(19.3 \%)$ \\
\hline Midwest & $28(16.9 \%)$ \\
\hline West coast & $25(15.1 \%)$ \\
\hline Southwest & $12(7.2 \%)$ \\
\hline Mid-Atlantic & $10(6.0 \%)$ \\
\hline Central & $9(5.4 \%)$ \\
\hline Northwest & $3(1.8 \%)$ \\
\hline U.S Territories, Alaska, Hawaii & $2(1.2 \%)$ \\
\hline \multicolumn{2}{|l|}{ RDN = Registered Dietitian Nutritionist } \\
\hline \multicolumn{2}{|c|}{$\begin{array}{l}\text { bCheck all that apply; percentages exceed } 100 \% \text { when summed } \\
\text { 'CEDRD =Certified Eating Disorder Registered Dietitian }\end{array}$} \\
\hline \multicolumn{2}{|c|}{${ }^{\mathrm{C}} \mathrm{CSSD}=$ Certified Specialist in Sports Dietetics } \\
\hline \multicolumn{2}{|c|}{ e LICSW=Licensed Social Worker } \\
\hline \multicolumn{2}{|l|}{ CDE $=$ Certified Diabetes Educator } \\
\hline \multicolumn{2}{|l|}{${ }^{8}$ CEDS $=$ Certified Eating Disorder Specialist } \\
\hline \multicolumn{2}{|l|}{$\begin{array}{l}{ }^{\mathrm{h}} \text { IOP=Intensive Outpatient Program; PHP= } \\
\text { Program }\end{array}$} \\
\hline
\end{tabular}

The majority of RDNs surveyed reported that the first time they were exposed to clients with eating disorder diagnoses was after completing their academic curriculum, i.e., as an entry level dietitian, dietetic intern, or early in their clinical career (Table 2). Of note, almost half of respondents reported that they were in their first job as an RDN when they began working with patients with eating disorder diagnoses with no prior clinical practice experience. Only about one in ten reported that they considered themselves an experienced clinician before adding eating disorder treatment into their practice; these RDNs had worked in diverse clinical, outpatient, or community settings previously.

In this sample, didactic education and/or mandatory clinical training on eating disorders care was reported by far fewer than the 20\% prevalence cut-off point chosen for display in Table 2. Fewer than 10\% reported having exposure to clients with ED diagnoses during their undergraduate training and even fewer reported experiences during graduate school. Only two respondents (I\%) reported that it was a required component of their undergraduate dietetics curriculum; another $15(8 \%)$ reported that it was offered as an undergraduate elective. Four respondents (2\%) stated that eating disorder education was required in their graduate school curriculum; another 26 (14\%) reported the option to choose a graduate elective course on eating disorders. Ten respondents (5\%) had a required rotation in their dietetic internship (DI) where they participated in the care of patients with eating disorder diagnoses; another 43 (24\%) had the ability to choose an elective DI rotation to secure training in ED treatment. Of note, $11 \%$ of respondents were working in paid positions providing care to patients with eating disorder diagnoses with reportedly no specialized education or training beyond their generalist RDN training.

The majority of respondents (around 80\%) reported self-directed post-professional educational opportunities as the predominant venue for gaining knowledge and skill in this practice specialty (Table 2): presentations at conferences, professional development workshops, and independent reading. Most reported receiving on-thejob training to acquire skills to work with ED clients; others used on-line webinars, and about half reported training from inter-professional education. Less commonly used were non-degree certificate training programs in ED treatment (18\%), volunteer experiences (19\%), grand rounds case discussions (13\%), and clinical supervision with colleagues or senior clinicians (13\%).

In addition to their routine job responsibilities, respondents voluntarily engaged in leadership activities with high frequency. Almost three-quarters served in a leadership role as a case manager. Most sought professional development opportunities at least monthly and more than two-thirds had professional supervision with a senior RDN on a regular basis. More than half served as mentors and preceptors for other dietitians. However, only 18\% of RDNs who serve in 
these advanced leadership roles reportedly received training to become a mentor or preceptor. Those who were trained in mentorship used resources from the Commission on Dietetic Registration, International Association of Eating Disorder Professionals, supervisors in work settings, or university resources. More than three-quarters of those who served as mentors precepted dietetic interns (77\%); 53\% mentored early career RDNs, 42\% mentored newly hired RDNs, 40\% trained undergraduates, $37 \%$ mentored experienced RDNs wanting ED training, 30\% mentored graduate students, and 28\% mentored non-RDN professionals (data not shown).

Few respondents (27\%) routinely collected outcomes data on their patients. Among the fewer than 50 RDNs who reported monitoring patient outcomes, the most commonly tracked data were weight/anthropometry (92\%), behavioral symptoms (85\%), intakes of calories, food, or supplements (70\%), nutritional biomarkers and lab values (55\%). Only about half of RDNs who monitored patient outcomes used validated, objective assessment tools to evaluate changes in risk or outcomes over the course of treatment. Outcomes data were rarely reported to others or published. Among the small group of respondents who did track patient outcomes, most used them for their own purposes to guide clinical practice; up to $32 \%$ reported summarizing outcomes data to present to colleagues at work or professional meetings; 10\% collected outcomes data for research and one respondent reported publishing patient outcomes in peer-reviewed journals. Respondents in our sample highly valued research and noted a paucity of research to inform their practice. When asked what would help them feel more confident in their practice, the most common response (reported by $72 \%$ of participants) was more published research on ED treatment protocols and outcomes.

More than half of respondents in the entire survey population (55\%) did not know the average length of stay for patients in their practice. Slightly more (59\%) did not know the average weight gain per week that was typically achieved by patients with a diagnosis of anorexia nervosa (AN) in their practice. Two-thirds of respondents (65\%) did not know what proportion of patients with an AN diagnosis restored weight to a BMI of 19 or 20 (a common therapeutic target) by the time they discharged from the treatment facility or left the RDN's practice.

Table 2. Training and Leadership Roles of Eating Disorder Dietitians

\section{Training $(n=\mid 82)$}

First exposure to clients with eating disorder diagnoses

Prior experience before taking first position working with ED ${ }^{b}$ clients

Sources of specialized education or training in the care of patients with eating disorders

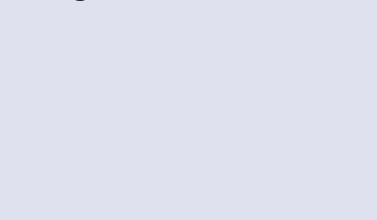

\section{Leadership $(n=182)$}

Leadership roles

\section{Responses with frequency $>20 \%$}

I was an entry level RDNa (28\%)

I was a dietetic intern (26\%)

I had some clinical experience, but was still junior (21\%)

I was an entry level RDN; this was my first job (43\%)

I had worked as a clinical dietitian before (4l\%)

I had worked in outpatient or private practice before (30\%)

Attending presentations/lectures/conferences (86\%)

Professional development workshops (86\%)

Reading published research on ED topics (82\%)

Reading professional newsletters or websites (82\%)

On-the-job training (80\%)

On-line training including webinars (72\%)

Reading books and articles on EDs in the lay press (70\%)

Interprofessional educational experiences (51\%)

An elective rotation during my dietetic internship (24\%)

\section{Responses with frequency $>20 \%$}

Seeks professional development at least monthly (84\%)

Coordinates care and serves as case manager (72\%)

Has professional supervision with senior RDNs (69\%)

Serves as a mentor or preceptor (60\%)

Tracking patient

Routinely collects outcomes data after initial assessment (27\%)

outcomes

Reports outcomes to supervisors or other professionals (up to $32 \%$ of those who track) 


\section{Job Responsibilities.}

Direct patient care responsibilities made up the largest portion of respondents' work time (Table 3). These work hours included individual nutrition counseling sessions, meeting with clients to adjust meal plans, performing documentation and charting, and tracking outcomes data. "Other" weekly patient-care activities articulated as write-in responses included client/family communications, food service management, meal outings, and complimentary care modalities such as mindfulness and yoga. Additional reported hours were spent in interdisciplinary patient care rounds, new patient assessments, communication with collaborating providers, family meetings, coached meals or exposure snacks, group education, and discharge planning.

Weekly responsibilities unrelated to direct patient care primarily included managing and supervising staff, marketing programs and services, engaging in clinical supervision or professional development, and billing or administrative work. "Other" weekly non-direct patient care activities named in write-in responses included social media communications and writing educational blog posts. Fewer than three hours per week, on average, were spent on each of the following activities: scholarly work, creating educational materials, teaching or lecturing, and participating in research.

Table 3. Job Responsibilities Reported by Eating Disorder Dietitians

Scope of Practice

Direct patient care responsibilities
Task

Individualized counseling

Meal plan adjustment meetings

Documentation and charting

Tracking outcomes data

Other patient care activities

Interdisciplinary rounds

New patient assessments

Collaborative communication

Family meetings

Coached meals/exposure

Group education

Discharge planning

Non-direct patient care responsibilities
Managing/supervising staff

Marketing programs/services

Clinical supervision/professional development

Billing/administrative paperwork

Other non-patient care activities

Scholarly activity

Creating educational materials

Teaching or lecturing

Participating in research
Weekly Hours

$16.7+/-8.8$

$8.4+/-8.7$

$7.2+/-8.0$

$4.7+/-7.9$

$3.8+/-2.2$

$3.6+/-3.3$

$3.4+1-2.0$

$3.4+/-3.6$

$2.8+/-3.2$

$2.6+/-1.5$

$2.0+1-1.3$

$1.5+/-1.4$

$3.9+/-6.2$

$3.6+/-3.5$

$3.2+/-2.1$

$3.1+/-2.9$

$2.9+1-1.0$

$2.4+/-2.3$

$2.1+1-1.3$

$1.8+/-1.3$

$1.0+/-1.3$
Job Satisfaction. Ratings of satisfaction with job, compensation, client caseload, and employer support for professional development are shown in Figure I along with ratings of job confidence. While more than half of respondents chose the highest ratings for job satisfaction (52\%) and confidence in their skills as providers of ED nutrition services (66\%), proportionately fewer were very satisfied with compensation (29\%), employer support for professional development (40\%), and client caseload (46\%). About 10\% reported actual discomfort with their usual caseload and 10\% reported not feeling supported by their employer for continuing education needs. 
Figure I. Proportion of Participants who Reported Somewhat or High Satisfaction with Job Indicators

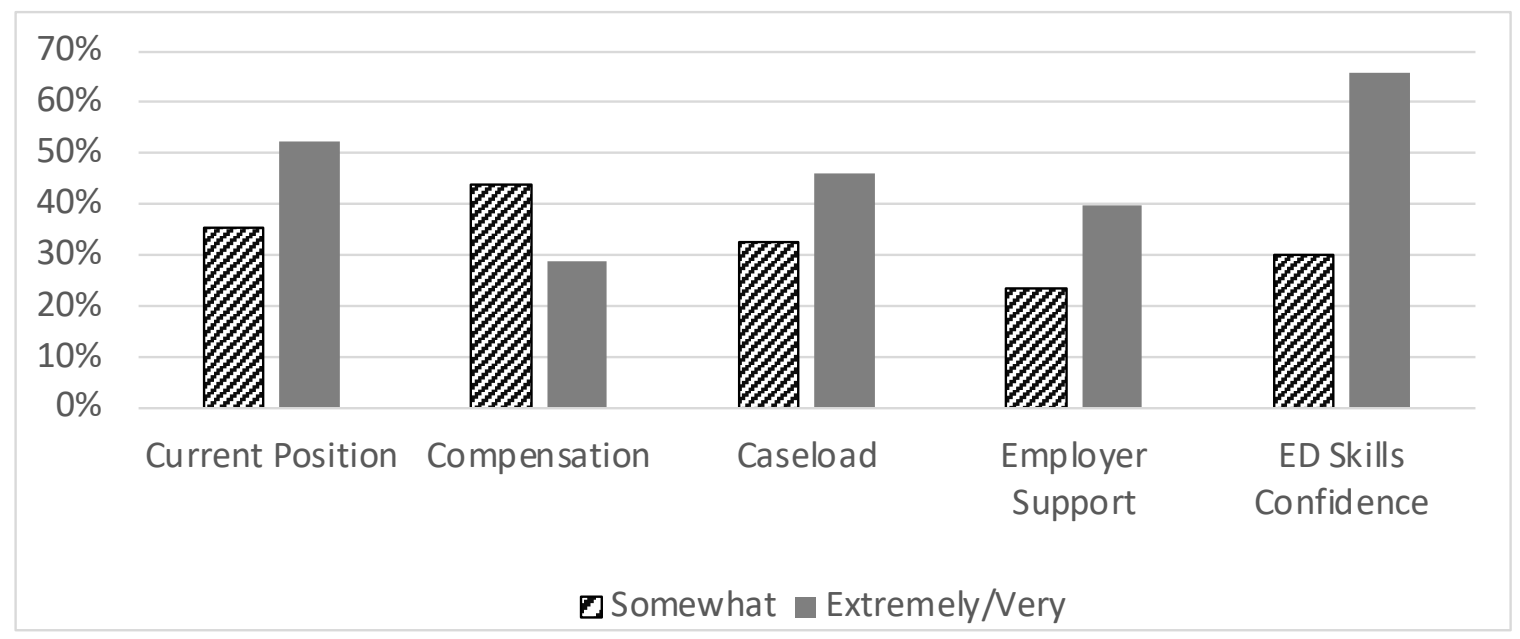

Participants' narratives provided in the text box at the end of the survey illuminated self-perceived obstacles and facilitators of job satisfaction (Figure 2). Compensation was one theme that respondents wrote about and 63\% $(n=115)$ reported their hourly wage. In this sample, those working for employers reported substantially lower compensation than those in private practice. Lowest hourly rates (mean, $\$ 27 /$ hour, range, $\$ 24$ to \$34) were reported by RDNs working in psychiatric hospitals $(n=6)$. Those working in medical hospitals $(n=12)$, ED treatment facilities $(n=28)$ or the college/ university setting $(n=6)$ all similarly reported an average hourly rate around $\$ 40$ (range, $\$ 19$ to $\$ 150$ ). RDNs in private practice $(n=63)$ reported earning $\$ 105 /$ hour on average (range, $\$ 20$ to $\$ 300$ ). Of note, our survey did not ask about other forms of compensation, such as benefits, employment status (hourly paid or contract work), nor did it differentiate between fee charged versus take-home pay in private practice.

Self-reported obstacles to job satisfaction included limited access to three essential resources: ED-specific training, professional development opportunities, and mentorship from expert clinicians. Lack of time to accomplish their workload coupled with a lack of understanding by employers of the scope of the RDN responsibilities in ED care beyond direct patient-care responsibilities, and professional burnout were also commonly cited in open-ended responses. Those working for employers were more likely to comment on high patient caseloads with added challenges related to the high acuity of patients with ED diagnoses requiring time and human resources to manage complex cases. Also cited were low rates of reimbursement for services, not feeling appreciated or valued by managers or other healthcare team members, and a general lack of understanding of the exceptionally high demands of caring for patients with ED diagnoses that are not experienced by RDNs in other work environments. Those who were dissatisfied with their employer's support for professional development reported budget constraints that left them responsible for the costs associated with continuing education, difficulty arranging time off or having to take unpaid time off to attend conferences or workshops, or few training resources being available to them in their work setting or geographic location. Among those working for employers, commonly cited contributors to dissatisfaction with pay included lower-than-market rates of pay in some organizations in spite of specialist training/credential and limited opportunities for career advancement. Inadequate insurance reimbursement was reported as a prime source of dissatisfaction in this sample, along with the high amount of non-direct patient care effort that is unbillable but required to responsibly care for patients with ED diagnoses.

Facilitators of job satisfaction included the professional community surrounding the RDN, the client community, and the private practice setting. RDNs who worked in private practice reported a level of autonomy over their caseloads and incomes with the freedom to set boundaries that distinguished their situation from those working in a facility setting. Respondents working in private practice reported prioritizing professional development and provided it regularly for themselves. Those who worked in a facility reported more satisfaction when they experienced support and advocacy from their managers, were well-compensated, had appropriate expectations for use of their time, and when employers allocated time and funding for professional development or pursuit of specialty credentials. 
Figure 2. Obstacles and Facilitators of Job Satisfaction among Eating Disorder Dietitians

\section{Obstacles}

Limited access to eating disorder-specific training and professional development or mentorship from expert clinicians

\section{Selected Illustrative Quotes}

- I'm basically self-taught through reading and webinars, with around one year of monthly supervision from a veteran $\mathrm{RDN}^{\mathrm{a}}$

- RDN mentorship is highly recommended. Wish it was part of job requirements and that companies provided reimbursement for this in some way.

- I do participate in a peer supervision group, which I administrate, but we are basically on the same level and don't always have new ideas for each other - we seem to get stuck on the same things.

- I learned the most working in an inpatient facility for 4 years.

- The bulk of my practice is not with $\mathrm{ED}^{\mathrm{b}}$ clients but with clients with disordered eating behaviors. I would like to increase my practice for ED clients, but without proper training, I don't feel comfortable doing so.

- [We need] more training in the psychology of eating, what constitutes normal eating, and how to counsel patients effectively. understanding that the scope of eating disorder practice includes more than direct patient care hours

Feeling burned out and overworked
Lack of time and

- We have 52 RDN hours per week and see 34 direct patients-hours per week - it is not enough time for anything except patients, charting and case consultation. No room for program development or professional development.

- While very satisfied with my job and so grateful for all my clients, my ideal work environment combines I:I counseling, groups, and research or curriculum development, but my current schedule's non-client time is dominated by rounds, emails, and charting.

- Lack of time to have the opportunity to thoroughly do non-direct patient care tasks because there is no compensation for them - needing to make sure I have time in my schedule for work I actually get compensated for sometimes leaves me burnt out, feeling resentful, and during busy times most likely decreases quality of patient care in terms of time to connect with treatment team, follow up with MDs for medical records/labs/etc.

- Treating patients with eating disorders regardless of the practice location is more than a full-time job.

- I am always behind on my work, and have experienced burnout. No time in the day for breaks.

- Would love resources from my company dedicated to preventing burn out.

- I feel as though practitioners are drawn to private practice because many are worn out in other jobs.

Compensation

- When working in the treatment setting, I felt RDNs were overworked and underpaid, and not supported to be able to do their jobs to the fullest.

- I contemplated pursuing the $\mathrm{CEDRD}^{\mathrm{c}}$ credential but cost was the prohibitive factor.

- Some insurance plans do not cover medical nutrition therapy for eating disorder diagnoses which can be barrier to obtaining nutrition services.

- The current insurance/political climate is making it much more difficult recently as clients want insurance coverage and companies are time-consuming, frustrating and often drag out payments for long periods. 
- I am in private practice but it is so important to have other dietitians to bounce cases off of or to give resources to help me. I am confident as an ED dietitian because I know I can't be on an island and do it alone.

- This is hard work! Support from colleagues is essential.

- It can be a lonely job. I stay connected with peers and supervision groups.

- It is a highly collaborative role with a high level of communication.

- Collaboration with other professionals (physicians, therapists, nurse practitioners) is necessary in areas of the country that don't have direct access to an outpatient treatment facility.

- This specialty is emerging so far as quite distinct from other RDN specialties - so much so that it feels like an entirely different profession. This requires continuous ED community and interaction.

- I am forever grateful for those in the field who have stepped up to provide resources and training -- a Godsend over the course of my career!

\begin{tabular}{|c|c|}
\hline Client Community & $\begin{array}{l}\text { - I love the intimacy with clients and colleagues, and it is a joy to see people recover } \\
\text { and reveal their "true self." } \\
\text { - I am so grateful for all of my clients. }\end{array}$ \\
\hline Private Practice Setting & $\begin{array}{l}\text { - I'm blessed to be able to provide appropriate care and be creative. I can employ } \\
\text { methods that make sense for the individual client without having to worry about } \\
\text { what administration will think. }\end{array}$ \\
\hline & $\begin{array}{l}\text { - I am currently in private practice after working for an ED treatment center for } \\
\text { many years. That experience greatly influenced my confidence to work in this area } \\
\text { of the field, and to feel competent in my knowledge and skills. }\end{array}$ \\
\hline
\end{tabular}

${ }^{a}$ RDN $=$ Registered Dietitian Nutritionist

${ }^{\mathrm{b}} \mathrm{ED}=$ Eating disorder

${ }^{c} \mathrm{CEDRD}=$ Certified Eating Disorder Registered Dietitian

\section{Discussion}

This survey research demonstrates the high desire for adequate education, training, professional development and clinical supervision expressed by RDNs working in ED care. Several factors that serve as obstacles to the provision of high-quality nutrition care services to individuals with eating disorders were identified: limited ED-related training in the dietetics curriculum; unmet needs for specialized training, professional development and mentorship; and difficulties conducting outcomes research that is needed to advance evidence-based practice. Improvements are needed to equip a workforce capable of meeting the needs of the underserved, growing, and highly complex ED patient population. In a way not previously documented, this research illuminates characteristics of RDNs' work settings that impact their confidence, job performance, engagement in outcomes research, and job satisfaction. Finally, this research identifies potential threats to the quality of care provided to patients with eating disorders, particularly the inverse relationship between clinician expertise and patient acuity combined with highest rates of burnout and low job satisfaction identified in the hospital and facility settings. These factors may contribute to the movement of experienced RDNs into private practice, leaving institutions and organizations with entry-level rather than experienced clinicians and risking detrimental impact on patient outcomes.

According to this survey, academic education and training regarding the care of patients with eating disorders is visibly inadequate at all levels of RDN preparation - undergraduate didactic programs in dietetics (DPD programs), most graduate programs, and most dietetic internships (DI). In the experience of the authors, the ED content in most DPD programs is limited to - at most - a few lectures in a medical nutrition therapy course covering ED diagnostic criteria, signs and symptoms, at risk populations, and the basic strategies of diagnosis-specific treatment interventions. One-quarter of survey respondents or more expressed beliefs that formal didactic education in undergraduate and/or graduate courses, training opportunities in the 
dietetic internship, and practicum/supervised training opportunities are needed to prepare for work in this specialty niche of practice. Several respondents echoed what one participant articulated as, "more training in the psychology of eating, what constitutes normal eating, and how to counsel patients effectively." The results of this survey have led us (the authors) to more questions than answers. But one clearly documented finding is that the vast majority of ED-specific education, training and expertise belonging to dietitians who responded to this survey has been acquired at their own expense, on their own time, and outside of the didactic and clinical training programs leading to the RDN credential.

In theory, one could assert that ED is a specialty area that most RDNs will not pursue, so why should the academic and training process to become registration-eligible devote much (or any) time to it? In fact, the editor of a professional journal that declined to publish our findings suggested that the recall of our survey respondents must be inaccurate because, "the study of eating disorders is covered in most basic nutrition textbooks." We would argue that the mere existence of a textbook chapter does not guarantee that the material is taught, let alone taught well or with sufficient depth to translate to clinical practice skill or competence. Nonetheless, considering the vast number of individuals who will experience an ED in their lifetime - almost 30 million in the U.S. alone (Deloitte, 2020) - and the fact that, of those who do receive care, the majority will be treated outside of a specialty ED facility, we find it unacceptable that even generalist RDN preparation fails to include adequate (or in some cases, any) practical experience in their care.

With the noted risks of disordered eating, orthorexia, and EDs among students of dietetics (Mahn \& Lordly, 2015; Reinstein, Koszewski, Chamberlin \& SmithJohnson, 1992; Drake, 1989) and practicing RDNs (Tremelling, Sandon, Vega \& Mcadams, 2017), the need for more DPD curriculum time focused on ED screening and prevention is underscored. One respondent commented on the universality of disordered eating in society noting, "more direct training [is needed in DPD programs] on screening for disordered eating and eating disorders across all practice settings from clinical dietetics to corporate wellness. All RDNs are probably interacting with people who have EDs, they just don't always know it, and sometimes they unintentionally do more harm than good." Only two dietetic internship programs in the country offer a specialized track in eating disorders (ACEND, 202I). Post-baccalaureate graduate programs and fellowship training programs in adolescent medicine that provide specialized ED training for RDNs do exist, but they are rare and highly competitive.

Insufficient training, inadequate knowledge and low confidence in identifying eating disorders has been reported among medical residents and practicing pediatricians (Pasold et al, 2018). This observation further substantiates the need for the RDN to hold specialty expertise. The expectation of advanced training for the eating disorder dietitian to serve an essential function on the ED treatment team is substantiated by the Academy's classification of three distinct levels of practice: competent, proficient, and expert (Tholking et al, 20II). Competent RDN practitioners are defined as entry level clinicians who are expected to gain on-thejob training and engage in tailored continuing education to increase knowledge and skills in a new focus area of practice. A proficient RDN practitioner is defined as having three or more years of experience in the focus area of practice and may acquire specialist credentials to demonstrate proficiency. An expert RDN practitioner is a recognized leader within the profession who has mastered the highest degree of skill or knowledge in their focus area with a commitment to evaluating and communicating targeted outcomes (Tholking et al, 20ll). It appears from our survey that a sizeable proportion of ED dietitians may be attempting to perform specialist level duties when they are not yet proficient practitioners. Dietitians in this sample who worked at higher levels of care and for employers were least likely to receive adequate specialized professional development; and they were also least likely to have earned a master's degree. In short, they are less likely to be competent or proficient clinicians. While data is lacking on treatment outcomes in relation to provider expertise, it is not hard to imagine the potential risks associated with high acuity patients being treated by inexperienced practitioners. These risks might include an inability to achieve the mental and physical health outcomes that serve as markers of recovery, as well as negative lived experiences of patients in ED treatment that interfere with adequate treatment duration or return to treatment when relapse occurs.

Participants in this study reported using a variety of resources to advance their skills beyond entry-level competence. Some required personal initiative as a student or early career professional; all required access to opportunities and mentors; the majority were postprofessional and had associated costs not necessarily 
reimbursed by employers. The burden and the cost of acquiring ED-specific training or advanced credentials to work in the ED specialty of dietetics falls to a great extent on the dietitians themselves. Coupled with low compensation and high caseloads, time off for professional development is an unattainable luxury that cannot be realized by many.

Since these realities have implications for quality of patient care, addressing the unmet need for eating disorder education and training for the RDN should be a priority for our profession. A 2018 publication from the Academy reported a knowledge gap between generalist RDNs and those with the CDE credential, citing the potential impact on the practice of evidencebased care and patient outcomes in diabetes care (Bisanz et al, 2018). Although our survey methodology was different, our response rate was substantially higher. Several of the themes that emerged from our study echoed what Bisanz et al (2018) identified as an overarching need for additional training on behavioral and counseling strategies across nutrition specialties like diabetes care. This was noted in spite of the extensive hours in the DPD curriculum and DI training programs that are traditionally dedicated to the care of individuals with diabetes, metabolic syndrome, and cardiometabolic conditions. Our data show that the same cannot be said about the care of individuals with eating disorders, suggesting that the knowledge gap for RDNs working in eating disorder care may be even more extreme. It is reasonable to draw parallels between the RDN role in diabetes care and ED care as both conditions have high rates of mortality, co-morbidity, and repeated hospital admission, along with lifelong needs for ongoing treatment at the outpatient level of care. Demands for qualified treatment professionals are consequently high in both specialty areas of practice.

The current study corroborates previously published data demonstrating that patient nutritional risk showed little correlation with the RDN providers' earned wage (Griswold \& Rogers, 2020). In our sample, the RDNs with the least amount of education and training, in general and in eating disorders specifically, were working at the highest levels of care with complex patients of the highest clinical acuity. These entry level clinicians often had low compensation, the highest patient caseloads, the least self-confidence in their skills, and limited access to professional development opportunities. In the 2019 compensation and benefits survey published by the
Academy (Griswold \& Rogers, 2020), the median wage earned by those working mostly with high-risk patients ( $\$ 31.76$ per hour) was nearly identical to the median wage earned by those treating lower-risk patients $(\$ 32.00$ per hour) (Griswold \& Rogers, 2020). That study did not investigate job satisfaction, however it is likely that these realities may translate into unfavorable impacts on patient care and patient outcomes, an investigation that merits additional research.

Preparing RDNs to contribute to scholarship that advances the evidence base for the practice of dietetics is a stated priority of the Academy (Academy of Nutrition \& Dietetics, 2020). Compared with $50 \%$ of RDNs overall (Griswold \& Rogers, 2020), two-thirds of the RDNs in this study sample held a master's degree, demonstrating a higher level of advanced education in this group. In spite of that, engagement in scholarship was remarkably low in our study sample. To conduct and publish research, RDNs need skills, confidence, time and resources that our respondents did not report having. Practice-based and outcomes research are required to advance the field; conducting this research is the duty of expert-level practitioners. Respondents valued and noted the need for more published research to guide ED clinical practice. Most relied on reading the literature as an accessible means of professional development, though the majority of ED dietitians in our sample were not contributing to the peer-reviewed literature. Most cited a lack of time in the context of their census-driven workload which can be deciphered as a lack of incentive from their employers or in the private practice setting to generate scholarly work. In the absence of widespread tracking of clinical data, most respondents in this study did not know basic information about patient outcomes that are often used as indicators of effectiveness of eating disorder treatment (Redgrave et al, 2015). The lack of RDN engagement in research gives cause for concern over the pace at which evidence-based best practices are advanced for specialty patient populations, like those with eating disorders, where RDN care is central to recovery.

Definitive outcomes research involving rigorous study designs to evaluate clinical nutrition interventions involving large numbers of patients is under-represented in the eating disorder literature. Hart et al. (2018) recently summarized the literature as it relates to dietetics practice in ED care, concluding that evidencebased guidelines for managing the nutritional needs of 
clients with eating disorders is lacking, causing patient care to be highly variable. RDNs can advance the literature by contributing case studies, survey research, needs assessments, and practice-based retrospective or prospective research. The importance of having the voice of the RDN in the literature serves many purposes including augmenting the ED treatment literature that our colleagues in psychology and medicine are actively contributing to, demonstrating the impact of the RDN on the ED treatment team and the contributions of nutrition interventions to patient outcomes, sharing best practices and innovations in nutrition care and counseling techniques, identifying appropriate assessment tools, disseminating new knowledge, posing new hypotheses, and increasing the capabilities and confidence of other RDNs in the field. This work is required to advance our profession and to achieve high quality patient care. RDNs need resources, support and opportunities to develop these skills and disseminate critical thoughts about clinical practice experiences.

Finally, this research identified several factors that serve as obstacles and others that facilitate job satisfaction among RDNs working in the field of eating disorders treatment. Factors identified as keys to job satisfaction in our study were similarly noted in a previous survey involving more than I,300 RDNs (Mortensen, Nyland, Fullmer \& Eggett, 2002) including self-employment, mentorship, professional engagement, and employer support for professional development.

The obstacles identified may be similar to those experienced by RDNs working in other specialty areas of the field, as well as generalists (Gingras, de Jonge, and Purdy, 2010), though feelings of burnout and being overworked might also reflect the complexity of the ED patient caseload that combines mental health challenges alongside significant behavioral, metabolic and physical manifestations. A poor understanding by employers of the diverse roles that the RDN assumes on the ED treatment team, particularly those that are not considered directly related to patient care, was clearly articulated in this study as problematic in settings where the RDN workload was closely tied to patient census. Our data demonstrate that RDNs in ED settings spend about $70 \%$ of their time in direct patient care, meaning that a full $30 \%$ of their time is spent in nondirect patient care activities (Table 3 ). These activities are not reimbursable and often not taken into account by employers when considering staffing patterns tied to patient census and caseloads. Time to engage in non-patient care activities was articulated as essential to building confidence in RDN skills, and this requires appropriate patient caseloads and reasonable workload expectations that are oftentimes lacking in settings where ED RDNs work.

Many duties performed by dietitians in our sample working in ED care may not be included in traditional RDN job descriptions or accounted for when determining RDN staffing patterns. If individuals charged with hiring RDNs are not familiar with the RDN roles and responsibilities in ED care, or if they are using general medical or behavioral staffing guidelines to allocate full-time equivalents (FTEs), there will be a mismatch between staffing plans and the actual demands of the job that could contribute to high caseloads and burnout. General behavioral health regulations often require only one nutrition assessment per patient per month and for an RDN to sign off on a monthly menu plan that then applies to all patients in the facility. This is in stark contrast to the weekly or bi-weekly nutrition counseling sessions and meal-plan adjustments, meal outings, food exposure challenges, family meetings, group education sessions, discharge planning, outcomes documentation and other activities reported by RDNs in our sample.

The main limitation of this study is its design. This was a cross-sectional survey capable only of producing descriptive information that can be used to generate hypotheses for future research. Nonetheless, with insights shared by almost 200 practitioners in this specialty niche of clinical practice, this research can serve as a call to action to prepare RDNs who are not only competent, but proficient and expert in the care of individuals with eating disorder diagnoses. It is important to note that these observations were drawn from a sample of RDNs who are members of IFEDD, an organization committed to addressing obstacles to quality of ED care. As such, the awareness of, commitment to and engagement with specialty training and professional development for ED treatment measured in our study sample is likely higher than one would observe in a population of generalist RDNs. While this could introduce some bias into our findings, these observations make the call to action more generalizable if the unmet need and the knowledge gap are truly larger than measured in our study. Other design limitations include a lack of differentiation between salaried versus contract employees, self-employed private practice/practice owners versus private practice 
employees, and other areas of specificity that may have further informed our interpretation of survey data.

The issues of RDN training and staffing discussed in this paper have wide-ranging impact through both direct effects on shortage of time to provide the best (or even adequate) care, and also on position longevity or its contrast, turnover due to burnout and low job satisfaction. This survey did not ask respondents to differentiate between paid versus unpaid hours worked, or to document the number of patients in the caseload in the context of hours worked. Given the limitations of our data, we are unable to determine how job satisfaction may have differed between participants who worked more hours or had more patients in their caseload. However, in both informal conversations with colleagues and formal supervisory and consulting relationships, authors Setnick and Quatromoni have each been privy to numerous observations and reports of RDNs in ED care working unpaid overtime to meet job expectations and/or their own high standards of patient care. So, while in the short-term unpaid RDN hours worked may protect patient well-being and support treatment outcomes, over time the chronicity of this situation may cause the overworked RDN to leave the institution for the more lucrative and independent world of private practice, creating an ongoing cycle of newer, underprepared RDNs working in organizations treating the highest acuity patients.

Of note, this study was conducted prior to the COVID-19 pandemic. The dramatic rise in eating disorder pathology attributed to the global pandemic resulted in tremendous spikes in ED treatment-seeking behavior and admissions to treatment (Cooper et al, 2020). Undoubtedly, the impact of the pandemic on the working conditions and caseloads of RDNs working in ED treatment was substantial but is not reflected in these observations.

\section{Conclusion}

RDNs working in eating disorder treatment have unique needs for education, training, and professional development that are not readily provided in the dietetics curriculum. This creates a knowledge gap among generalist RDNs that could affect the quality of ED patient care, treatment outcomes and patient experiences of treatment. Several factors influence job satisfaction of RDNs in the ED specialty, including client caseloads, compensation, practice setting and professional networks that offer support. This research identifies several priority areas that, if addressed, could strengthen the RDN workforce, contribute to the knowledge base, and improve the delivery of evidencebased nutrition practice in the care of persons with eating disorders.

Acknowledgements: The authors would like to acknowledge the members of the International Federation of Eating Disorder Dietitians (IFEDD) who took part in this survey and the dietitians of Walden Behavioral Care, Inc who pilot tested our survey. We thank the graduate students in the M.S. in Statistical Practice (MSSP) program at Boston University who assisted with building the survey in its online platform.

\section{Author Biographies}

Jessica Setnick, MS, RDN, LD, CEDRD-S is the owner of Understanding Nutrition, PC and founder of the CDR Navigator. Jessica has been on the front lines of eating disorder treatment since 1998, developing and teaching eating disorder treatment protocols used globally. She shares her wealth of knowledge and experience in every possible format, including the Eating Disorders Boot Camp: Training Workshop for Professionals online course, books including The Eating Disorders Clinical Pocket Guide and The Academy of Nutrition and Dietetics Pocket Guide to Eating Disorders, as a CEDRD Supervisor and mentor to treating professionals around the world, and through on-site and virtual trainings.

Kerrin Meseck, MS, RDN was a graduate student of nutrition at Boston University at the time this research was conducted. Currently, she is a Sports Nutrition Fellow in the Department of Athletics at Duke University in Durham, North Carolina, serving the nutrition needs of a variety of student-athlete populations.

Jordan Tackett, MS, RDN, LDN, CNSC was a graduate student of nutrition at Boston University at the time this research was conducted. She is now an RD-II at Arkansas Children's Hospital working in both inpatient and outpatient settings, primarily treating adolescents with eating disorder diagnoses.

Paula A. Quatromoni, DSc, MS, RDN, LDN is an Associate Professor and Chair of the Department of Health Sciences at Sargent College of Health and Rehabilitation Sciences at Boston University where she also holds faculty appointment in the School of Public Health (Epidemiology) and the School of Medicine (Graduate Medical Sciences). Dr. Quatromoni conducts 
research on eating disorders treatment and prevention and is a senior consultant to the eating disorders treatment program at Walden Behavioral Care. A Framingham Study investigator, her research program includes a focus on dietary quality and chronic diseases, specifically cardiometabolic disease. She teaches a global course on the health promoting benefits of the Mediterranean lifestyle in Padua, Italy.

Author Contributions: JS and PQ designed the study and developed the survey. PQ secured IRB approval, pilot tested the survey, collected the study data and wrote the first draft of the manuscript. JS provided access to the IFEDD listserv and communicated with members to provide the survey link. JT participated in data summarization and KM participated in literature reviews and manuscript drafting. All authors reviewed and contributed to revisions to produce the final manuscript.

Corresponding Author and Requests for Reprints: Dr. Paula Quatromoni, Chair \& Associate Professor, Department of Health Sciences, Boston University, 635 Commonwealth Ave, Boston, MA 02215; paulaq@bu.edu; 617-353-5797.

IRB Approval: Study protocols and the survey were approved by the Boston University Institutional Review Board.

Funding/Financial Disclosure: This project was unfunded.

Conflict of Interest Disclosure: $P Q$ is a senior consultant for Walden Behavioral Care, Inc. JS is the owner of Understanding Nutrition and founder of the IFEDD organization.

\section{References}

Academy of Nutrition \& Dietetics. (2020). Academy research priorities. An agenda to advance nutrition and dietetics knowledge \& practice. https://eatrightpro.org/-/media/ eatrightpro-files/research/research-priorities-final-report. pdf

Accreditation Council for Education in Nutrition and Dietetics (ACEND). (2021, August 2). https://www.eatright.org/ acend/accredited-programs/dietetic-internships

American Psychiatric Association (APA). (2000). American Psychiatric Association practice guidelines for the treatment of patients with eating disorders (revision). American Journal of Psychiatry, 157(suppl 1), 1-39.

American Psychiatric Association (APA). (2013). Diagnostic and Statistical Manual of Mental Disorders, 5th edition (DSM5). Washington, D.C.: American Psychiatric Association Publishing.

American Psychiatric Association (APA). (2016). Handbook of Assessment and Treatment of Eating Disorders. Walsh, B. T., Attia, E., Glasofer, D. R., \& Sysko, R., editors). Washington, D.C.: American Psychiatric Association Publishing.

Bisanz, K., Parker, A., Byrne, C., Parker, S. A., Thomas, J., Mancino, J., \& Hand, R. K. (2018). Identification of generalist Registered Dietitian Nutritionist knowledge gaps in diabetes medical nutrition therapy compared to diabetescredentialed Registered Dietitian Nutritionists: results of a survey to inform educational opportunities. Journal of the Academy of Nutrition \& Dietetics, II8(7), 1312-1321. https:// doi:10.1016/j.jand.2018.01.009

Cairns, J., \& Milne, R. L. (2006). Eating disorder nutrition counseling: strategies and education needs of Englishspeaking dietitians in Canada. Journal of the American Dietetic Association, 106(7), 1087-1094. https://doi:10.1016/j. jada.2006.04.025

Cooper, M., Reilly, E. E., Siegel, J. A., Coniglio, K., SadehSharvit, S., Pisetsky, E. M., \& Anderson, L.M. (2020). Eating disorders during the COVID-19 pandemic and quarantine: an overview of risks and recommendations for treatment and early intervention. Eating Disorders. https://doi: 10.1080/106 40266.2020.179027I

Deloitte Access Economics. (2020). The Social and Economic Cost of Eating Disorders in the United States of America: A Report for the Strategic Training Initiative for the Prevention of Eating Disorders and the Academy for Eating Disorders. Available at: https://www.hsph.harvard.edu/striped/ report-economic-costs-of-eating-disorders/

Drake, M. A. (1989). Symptoms of anorexia nervosa in female university dietetic majors. Journal of the American Dietetic Association, 89(I), 97-98.

Gingras, J., de Jonge, L. A., \& Purdy, N. (2010). Prevalence of dietitian burnout. Journal of Human Nutrition and Dietetics, 23(3), 238-243. https://doi: 10.1111/j.1365$277 \times .2010 .01062 . \times$ 
Gordon, K. H., Brattole, M. M., Wingate, L. R., \& Joiner, T. E. (2006). The impact of client race on clinician detection of eating disorders. Behavior Therapy, 37(4), 319-325. https:// doi:10.1016/j.beth.2005.12.002

Griswold, K., \& Rogers, D. (2020). Compensation and Benefits Survey 2019. Journal of the Academy of Nutrition \& Dietetics, 120(3), 448-464. https://doi:10.1016/j.jand.2019.12.015

Harris, J. E., Gleason, P. M., Sheean, P. M., Boushey, C., Beto, J.A., \& Bruemmer, B. A. (2009). An introduction to qualitative research for food and nutrition professionals. Journal of the American Dietetic Association, 109(1),80-90. https://doi:10.1016/j.jada.2008.10.018

Hart, S., Marnane, C., McMaster, C., \& Thomas, A. (2018). Development of the "Recovery from Eating Disorders for Life" Food Guide (REAL Food Guide) - a food pyramid for adults with an eating disorder. Journal of Eating Disorders, 6(6), I-II. https://doi:I0.1186/s40337-018-0192-4

International Federation of Eating Disorder Dietitians (IFEDD). (2021, August 2). https://www.eddietitians.com

Mahn, H. M., \& Lordly, D. (2015). A review of eating disorders and disordered eating amongst nutrition students and dietetic professionals. Canadian Journal of Dietetic Practice \& Research, 76(I), 38-43. https://doi: 10.3148/cjdpr-20I4-03I

Marques, L., Alegria, M., Becker, A. E., Chen, C., Fang, A., Chosak, A., \& Diniz, J. B. (20II). Comparative prevalence, correlates of impairment, and service utilization for eating disorders across U.S. ethnic groups: Implications for reducing ethnic disparities in health care access for eating disorders. The International Journal of Eating Disorders, 44(5), 412-420. http://doi.org//0.1002/eat.20787

Mortensen, J. K., Nyland, N. K., Fullmer, S., \& Eggett, D. L. (2002). Professional involvement is associated with increased job satisfaction among dietitians. Journal of the American Dietetic Association, I02(10), 1452-1454. https:// doi:10.1016/s0002-8223(02)90321-4

Ozier, A. D., \& Henry B. W. (2010). Preliminary report on dietitians' views and confidence related to nutrition care for eating disorders. Infant, Child, \& Adolescent Nutrition, 2(2), |06-111.

Ozier, A. D., \& Henry, B. W. (20II). Position of the American Dietetic Association: nutrition intervention in the treatment of eating disorders. Journal of the American Dietetic Association, III (8), 1236-124I. https://doi: 10.1016/j. jada.2011.06.016

Pasold, T. L., Woods, J. L., Portilla, M. G., Nesmith, J. D., \& Boateng, B. A. (2018). An examination of eating disorder education and experience in a I-month adolescent medicine rotation: what is sufficient to foster adequate self-efficacy? International Journal of Adolescent Medicine and Health, 32(5), 2017-0212. https://doi:10:1515/ijamh-2017-0212
Redgrave, G. W., Coughlin, J. W., Schreyer, C. C., Martin, L. M., Leonpacher, A. K., Seide, M., Verdi, A. M., Pletch, A., \& Guarda, A. S. (2015). Refeeding and weight restoration outcomes in anorexia nervosa: challenging current guidelines. International Journal of Eating Disorders, 48(7), 866-873. https://doi:I0.1002/eat.22390

Reinstein, N., Koszewski, W. M., Chamberlin, B., \& SmithJohnson, C. (1992). Prevalence of eating disorders among dietetics students: does nutrition education make a difference? Journal of the American Dietetic Association, 92(8), 949-953.

Setnick, J. \& Johnson, M. (2012). Interventions used in nutrition counseling for eating disorder treatment: Survey results. SCAN'S PULSE, 3I(3), I2-I4.

Tholking, M. M., Mellowspring, A. C., Eberle S. G., Lamb, R. P., Myers, E. S., Scribner, C., Sloan, R. F., \& Wetherall, K. B. (20II). American Dietetic Association: Standards of practice and standards of professional performance for Registered Dietitians (competent, proficient, and expert) in disordered eating and eating disorders (DE and ED). Journal of the American Dietetic Association, III (8), I2421249.e37. https://doi:10.1016/j.jada.2011.05.021

Tremelling, K., Sandon, L., Vega, G. L., \& Mcadams, C. J. (2017). Orthorexia nervosa and eating disorder symptoms in Registered Dietitian Nutritionists in the United States. Journal of the American Dietetic Association, 117(10), 16121617. https://doi:10.1016/j.jand.2017.05.001

World Health Organization (WHO). (1993). The ICD-I0 Classification of Mental and Behavioural Disorders. World Health Organization. 